\title{
Percutaneous pulmonary valve implantation with the Venus P-valve: clinical experience and early results
}

\author{
Worakan Promphan, ${ }^{1}$ Pimpak Prachasilchai, ${ }^{1}$ Suvipaporn Siripornpitak, ${ }^{3}$ Shakeel A. Qureshi, ${ }^{2}$ \\ Thanarat Layangool ${ }^{1}$ \\ ${ }^{1}$ Pediatric Heart Center, Queen Sirikit National Institute of Child Health, College of Medicine, Rangsit University; \\ ${ }^{2}$ Department of Radiology, Faculty of Medicine, Ramathibodi Hospital, Mabidol University, Bangkok, Thailand; \\ ${ }^{3}$ Department of Paediatric Cardiology, Evelina London Children's Hospital, Guy's and St Thomas' NHS Foundation \\ Trust, London, United Kingdom
}

\begin{abstract}
Background: At present, the exclusion for percutaneous pulmonary valve implantation for free pulmonary regurgitation after tetralogy of Fallot repair includes an unfavourably large right ventricular outflow tract. Objective: To report feasibility and early experience with a recently developed transcatheter heart valve, Venus $\mathrm{P}$-valve ${ }^{\mathrm{TM}}$, implanted in six patients with severe pulmonary regurgitation with large right ventricular outflow tracts. Patients: There were two female patients and four male patients. The median age of the patients was 18.5 years, and the mean body weight was $53.8 \mathrm{~kg}$. All the patients were in NYHA class II and had severe pulmonary regurgitation after previous transannular patch repair of tetralogy of Fallot. The median time after the last surgical operation was 13.5 years. Results: The Venus P-valve ${ }^{\mathrm{TM}}$ was successfully implanted in all the patients with implanted valve diameters ranging from 24 to $32 \mathrm{~mm}$. The mean fluoroscopy time was 29.8 minutes. None of the patients had significant outflow tract gradient or pulmonary regurgitation immediately after valve implantation. Only one patient had unexpected mild proximal valve migration to the right ventricular body during withdrawal of the delivery system. It caused mild paravalvar leak and significant tricuspid regurgitation. At 6 months follow-up, the median of right ventricular end-diastolic volume indices decreased from 146 to $108 \mathrm{ml} / \mathrm{m}^{2}$ ( $\mathrm{p}$-value $=0.046$ ). The Doppler systolic peak gradient across the valve ranged from 4 to $40 \mathrm{mmHg}$, and there was no evidence of stent fracture on fluoroscopy or structural valve failure. Conclusion: The Venus P-valve ${ }^{\mathrm{TM}}$ can be implanted successfully and effectively in patients with severe pulmonary regurgitation and a large right ventricular outflow tract. The early results with this valve are encouraging.
\end{abstract}

Keywords: Pulmonary regurgitation; percutaneous pulmonary valve implantation; Venus P-valve ${ }^{\mathrm{TM}}$

Received: 25 December 2014; Accepted: 17 May 2015; First published online: 19 June 2015

$\mathrm{P}$ ERCUTANEOUS PULMONARY VALVE IMPLANTATION IS a recognised alternative to repeated surgery in those patients who develop significant pulmonary regurgitation with or without right ventricular dysfunction after previous surgical repair. ${ }^{1}$ At present,

Correspondence to: W. Promphan, Pediatric Heart Center, Queen Sirikit National Institute of Child Health, 420/8 Rajvithi Road, Ratchathewi District, Bangkok 10400, Thailand. Tel: +662 354 8327; Fax: +662 354 8327; E-mail: wprompha@icloud.com however, exclusions for percutaneous valve implantation include unfavourably large right ventricular outflow tracts or those patients with native right ventricular outflow tracts or those in whom there is no stenosis in the right ventricular outflow tract. ${ }^{2-4}$

The Venus P-valve ${ }^{\mathrm{TM}}$ (Venus Medtech, Shanghai, China) is a recently developed self-expanding transcatheter heart valve, designed to adapt to a dilated right ventricular outflow tract. A report from an 
experimental study has demonstrated excellent valve function after implantation. ${ }^{5}$ Recently, Cao et $\mathrm{al}^{6}$ reported initial satisfactory results after Venus $\mathrm{P}$-valve ${ }^{\mathrm{TM}}$ implantation in five patients. The aim of our study was to report the feasibility and the early results of percutaneous implantation of the Venus $\mathrm{P}$-valve ${ }^{\mathrm{TM}}$ in the pulmonary position in six patients. The local institutional ethics committee approved this study.

\section{Materials and methods}

\section{Patients}

The indications for percutaneous pulmonary valve implantation were tetralogy of Fallot patients after previous surgical repair using transannular patch technique, who fitted the following inclusion criteria: severe pulmonary regurgitation on transthoracic echocardiogram ${ }^{7}$ and pulmonary regurgitant fraction $>30 \%$ on cardiac magnetic resonance study, increased right ventricular end-diastolic volume index $>150 \mathrm{ml} / \mathrm{m}^{2,8}$ unless right ventricular ejection fraction is $<45 \%$ in the presence of lower right ventricular end-diastolic volume index, symptoms such as deterioration of functional class, shortness of breath, the pulmonary valve annulus or conduit size of $>18 \mathrm{~mm}$ and $<30 \mathrm{~mm}$ from cardiac MRI, no significant right ventricular outflow tract or main pulmonary artery narrowing, and no significant obstruction of the proximal branches of the pulmonary artery. The patients who were excluded were those with body weight $<30 \mathrm{~kg}$, occluded central veins, and unfavourable right ventricular outflow tract anatomy, such as potential for coronary artery compression, or aneurysmal dilation, or tortuosity of the main pulmonary artery. Furthermore, patients with a pyramid-shaped right ventricular outflow tract were considered unsuitable for implantation of the Venus P-valve.

Between May and December, 2013, 23 patients were evaluated for the possibility of further valve replacement. All the patients were initially evaluated by transthoracic echocardiography to assess: the right ventricular dimension and function, severity of tricuspid regurgitation and right ventricular systolic pressure estimation, right ventricular outflow tract gradient from the Doppler velocity, ${ }^{9}$ and the degree of pulmonary regurgitation by color flow Doppler echocardiography. ${ }^{7}$ Subsequently, cardiac MRI was performed to define the size and the anatomy of the right ventricular outflow tract and pulmonary artery, in order to measure the left and right ventricular volumes and functions and to calculate the pulmonary regurgitant fraction.

In all, six patients fitted the inclusion criteria and underwent percutaneous implantation of the Venus
$\mathrm{P}$-valve ${ }^{\mathrm{TM}}$. There were four male and two female patients, ranging in age between 16 and 21 years (median 18.5 years) and ranging in weight between 35 and $69 \mathrm{~kg}$ (mean $53.8 \mathrm{~kg}$ ). All the patients had undergone complete correction of tetralogy of Fallot at ages ranging from 4 to 6.5 years. All the patients had severe pulmonary regurgitation and were in NYHA functional class II. Each patient and/or parent signed the informed consent before the procedure. Percutaneous Venus P-valve ${ }^{\mathrm{TM}}$ implantation was considered on compassionate use basis.

Of the remaining 17 excluded patients, 10 had main pulmonary artery diameters in excess of $30 \mathrm{~mm}$ or had unfavourable right ventricular outflow tract/ pulmonary artery anatomy such as short pyramidshaped right ventricular outflow tract or acute takeoff angle of the left pulmonary artery and were referred for surgical valve replacement; seven patients, who had pulmonary regurgitation but with no right ventricular volume overload or right ventricular systolic dysfunction, have been managed conservatively.

\section{Pre-procedure evaluation}

Between 3 and 6 months before the valve implantation procedure, cardiac catheterisation was performed for complete haemodynamic assessment and measurements of the right ventricular outflow tract and pulmonary artery pressures and dimensions. Angiograms were performed in the main pulmonary artery and right ventricular outflow tract in the antero-posterior or right anterior oblique with cranial angulation and lateral projections. Measurements of the maximum systolic diameter of the right ventricular outflow tract, the main pulmonary artery at the mid-part and its bifurcation, the maximum systolic diameter of the proximal and distal pulmonary artery branches, and the length from the right ventricular outflow tract to the pulmonary artery bifurcation were obtained (Fig 1). Simultaneous left coronary angiography and inflation of a sizing balloon in the main pulmonary artery were routinely performed to assess the expansibility and the diameters as well as the proximity of the left coronary artery to the right ventricular outflow tract. The reason for the pre-procedural cardiac catheterisation was to provide essential information for the manufacturing company (Venus Medtech) to manufacture a suitable selection of valves for each patient. This process can take up to 4 weeks.

\section{Valve and delivery system}

The Venus P-valve ${ }^{\mathrm{TM}}$ consists of a stent of a Nitinol frame, and the valve leaflets are made of porcine pericardium preserved in low-concentration solutions of buffered gluteraldehyde and are hand-sewn to the 

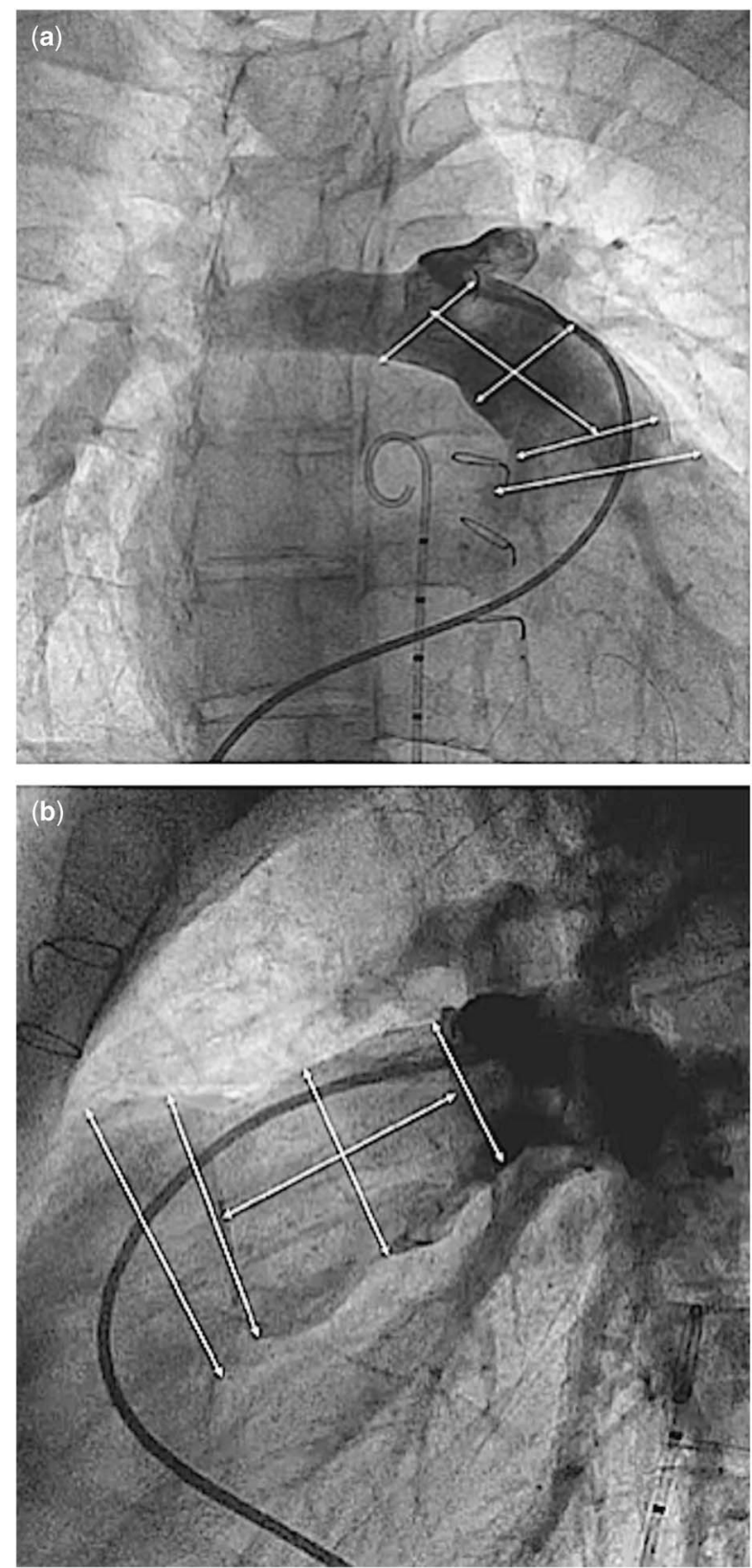

Figure 1.

Angiographic measurements in right anterior oblique (a) and lateral projections (b).

multi-level self-expanding Nitinol frame. The frame has proximal and distal flares to anchor the valve in the right ventricular outflow tract and pulmonary artery bifurcation. The proximal flare is completely covered by pericardial tissue, whereas the distal flare is an open cell wire frame allowing access into the pulmonary artery branches. The middle part is a fully covered housing of the valve intended to expand in the main pulmonary artery. For ease of identification, there are three radiopaque platinum markers at the proximal flare to identify the valve location. The diameters and the lengths of the middle part range from 18 to $34 \mathrm{~mm}$ (with $2 \mathrm{~mm}$ increments) and from 20 to $35 \mathrm{~mm}$ (with $5 \mathrm{~mm}$ increment), respectively. After cardiac magnetic resonance and angiographic evaluation, the valve length can be selected to match the length of the main pulmonary artery, in order to reduce the possibility of obstruction of the right ventricular body or pulmonary artery branches and to reduce paravalvar leak. The proximal and distal flare diameters are $10 \mathrm{~mm}$ larger than the middle segment. There are two small "ears" at the proximal part of the valve for attachment to the delivery system.

There are two types of Nitinol frames - the modular design and the unibody design. The modular design (Fig 2) is the first-generation design valve that has three sections - distal, proximal, and central - as individual modules and are connected together by surgical sutures. This design can have each module adjusted easily according to the patient anatomy. The next-generation of frames is the unibody design (Fig 3). The frame is made of a single Nitinol tube by laser slotting and shape setting. This design improves the frame integrity; however, manufacturing of the different sizes to fit the anatomy of all the patients is more time-consuming and costly.

The delivery system (Fig 4) consists of a 20-22 Fr capsule and a 16 Fr 100-cm-long shaft, with a rotating handle for deployment of the valve. The valve prosthesis is loaded into the capsule by submerging the Nitinol frame in sterilised cold saline solution and crimping the frame with a crimper provided by the manufacturer.

\section{Procedure and follow-up}

All the procedures were performed under general anaesthesia and access was obtained through both the femoral veins and one femoral artery. Heparin $100 \mathrm{U} / \mathrm{kg}$ was administered to maintain activated clotting time of $>250$ seconds. Although transoesophageal echocardiography was used during the procedure to monitor the right ventricular outflow tract before and after the valve implantation, it was not used routinely. Haemodynamic assessment was repeated with recording of the right ventricular, main pulmonary artery, and aortic pressures. The right ventricular outflow tract and pulmonary artery dimensions were re-assessed from the angiograms in the antero-posterior or right anterior oblique with cranial angulation and lateral projections. A $260-\mathrm{cm}-$ long $0.035^{\prime \prime}$ Lunderquist extra-stiff guide wire (Cook Medical, Bloomington, IN, United States of America) was positioned in the distal left lower pulmonary artery branch. Before valve implantation, balloon interrogation of the right ventricular outflow tract was repeated with a low-pressure 34-mm diameter $4-\mathrm{cm}$-long Amplatzer ${ }^{\mathrm{TM}}$ Sizing Balloon 

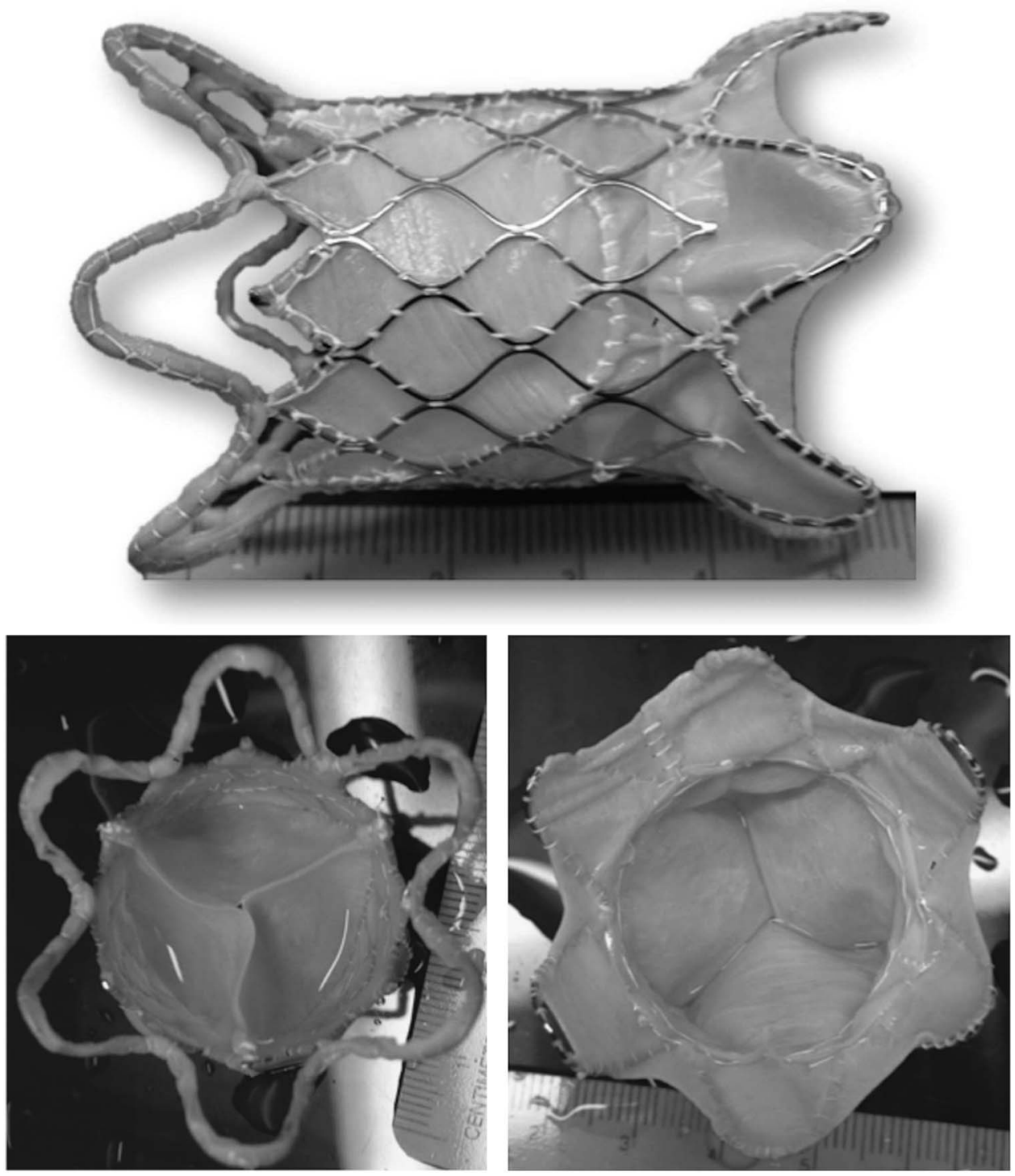

Figure 2 .

The modular design of the Venus P-valve ${ }^{T M}$.

Catheter (St. Jude Medical, Saint Paul, MN, United States of America) before the final valve selection (Fig 5). The selected valve diameter was $2-4 \mathrm{~mm}$ larger than the balloon inflation diameter at its waist, whereas the selected mid-body length was equivalent to the distance from the right ventricular outflow tract to pulmonary artery bifurcation. After preparation of the valve with prolonged rinsing with $2000 \mathrm{ml}$ of normal saline for at least 10 minutes, the valve was manually crimped in a bath of cold normal saline onto a 20-22 Fr delivery system. The valve assembly was passed through a $22 \mathrm{Fr} \mathrm{Check-Flo}{ }^{\circledR}$ Performer Extra-Large Introducer sheath (Cook Medical) and manipulated over the Lunderquist guide wire. The distal carrot tip of the assembly was positioned in the proximal left pulmonary artery.
Frequent check angiograms through a pigtail catheter placed in the main pulmonary artery were performed, as the distal flare of the valve was slowly deployed by clockwise rotation of the releasing knob. The valve position was adjusted after check angiograms before it was fully deployed. When the middle segment of the valve is exposed, if it is fully opposed to the main pulmonary artery, and because this stent segment is fully covered, there may be hypotension or bradycardia from low pulmonary blood flow for a brief period. The valve has to be deployed rapidly to allow normalisation of the cardiac output. After deployment, the right ventricular and pulmonary artery pressures were measured and angiography in the main pulmonary artery was repeated (Fig 6). Haemostasis of the femoral venous access site was achieved with a Perclose 

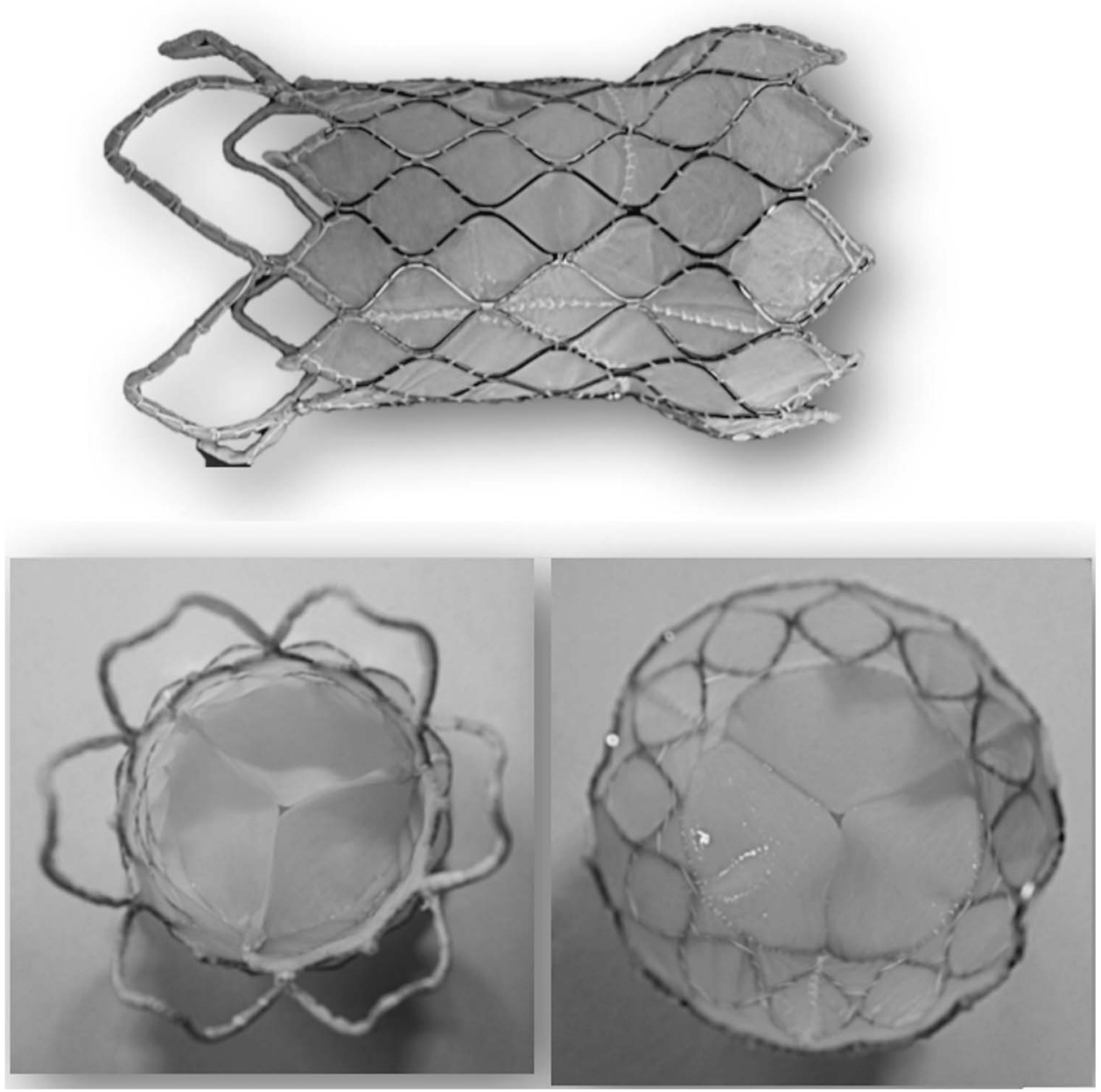

Figure 3.

The unibody design of the Venus P-valve ${ }^{T M}$.

(a)

(b)

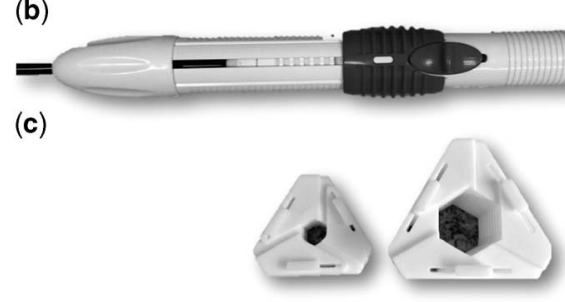

Figure 4 .

The Venus P-valve delivery system demonstrating a nose-cone/carrot with a radio-opaque tip capsule for valve loading (a), a bandle with slow and quick releasing knobs (b), and valve crimper (c).

ProGlide $^{\circledR}$ 6Fr Suture-Mediated Closure System (Abbott Vascular, Santa Clara, CA, United States of America) and manual compression of the smaller venous/arterial access sites.

Intravenous cefazolin $100 \mathrm{mg} / \mathrm{kg} / \mathrm{day}$ was administered for the initial 24 hours in all the patients.
Continuous infusion of heparin $10 \mathrm{U} / \mathrm{kg} /$ hour was administered for 24 hours after the procedure. This was changed to sub-cutaneous enoxaparin at a dose of $1 \mathrm{mg} / \mathrm{kg} /$ dose every 12 hours for an additional 2 days. The patients were discharged on oral aspirin $3-5 \mathrm{mg} /$ $\mathrm{kg} /$ day for at least 6 months. The patients were assessed on day 1 after the procedure and were scheduled for outpatient visits at 1,3 , and 6 months and yearly thereafter. The follow-up included clinical evaluation, electrocardiogram, chest X-ray, and transthoracic echocardiography. In addition, at 6 months after the procedure, cardiac magnetic resonance and fluoroscopy were performed to assess the function of the implanted valve, framework integrity, and changes in right ventricular dimensions and function.

\section{Statistics}

Continuous variables are expressed as mean $\underline{ \pm}$ standard deviation or median (interquartile range, IQR), whereas categorical variables are presented as numbers. Comparison of parameters before and after 


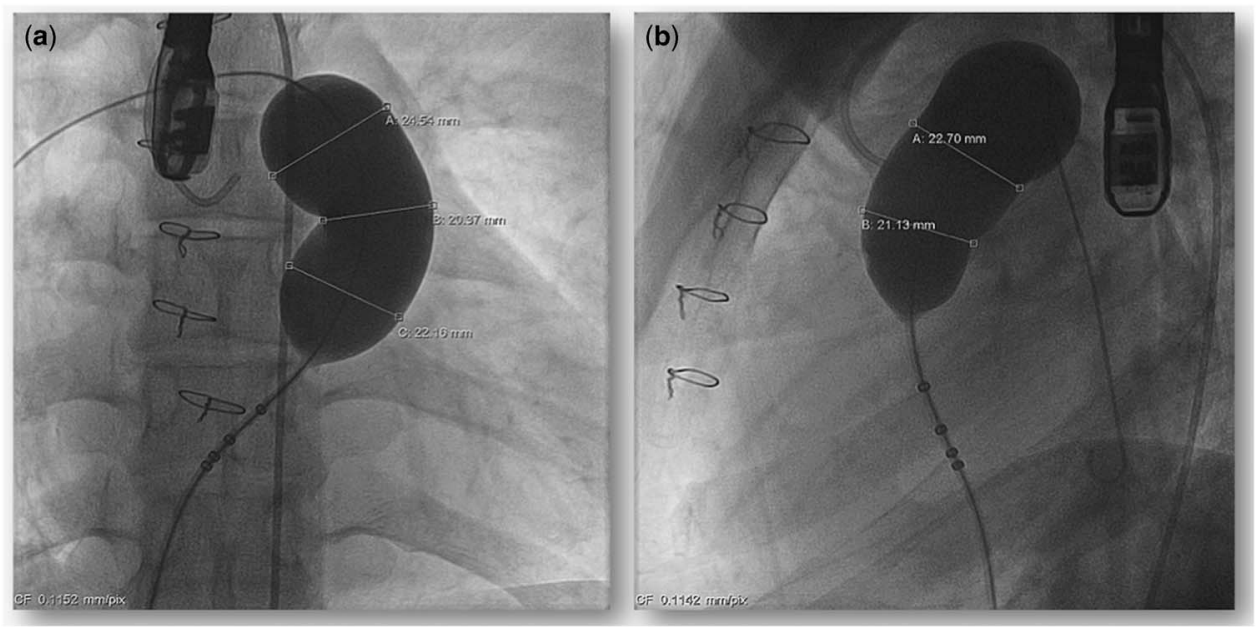

Figure 5.

Measurement of the stretch diameter by a large sizing balloon in the antero-posterior with cranial angulation (a) and the lateral (b) projections.
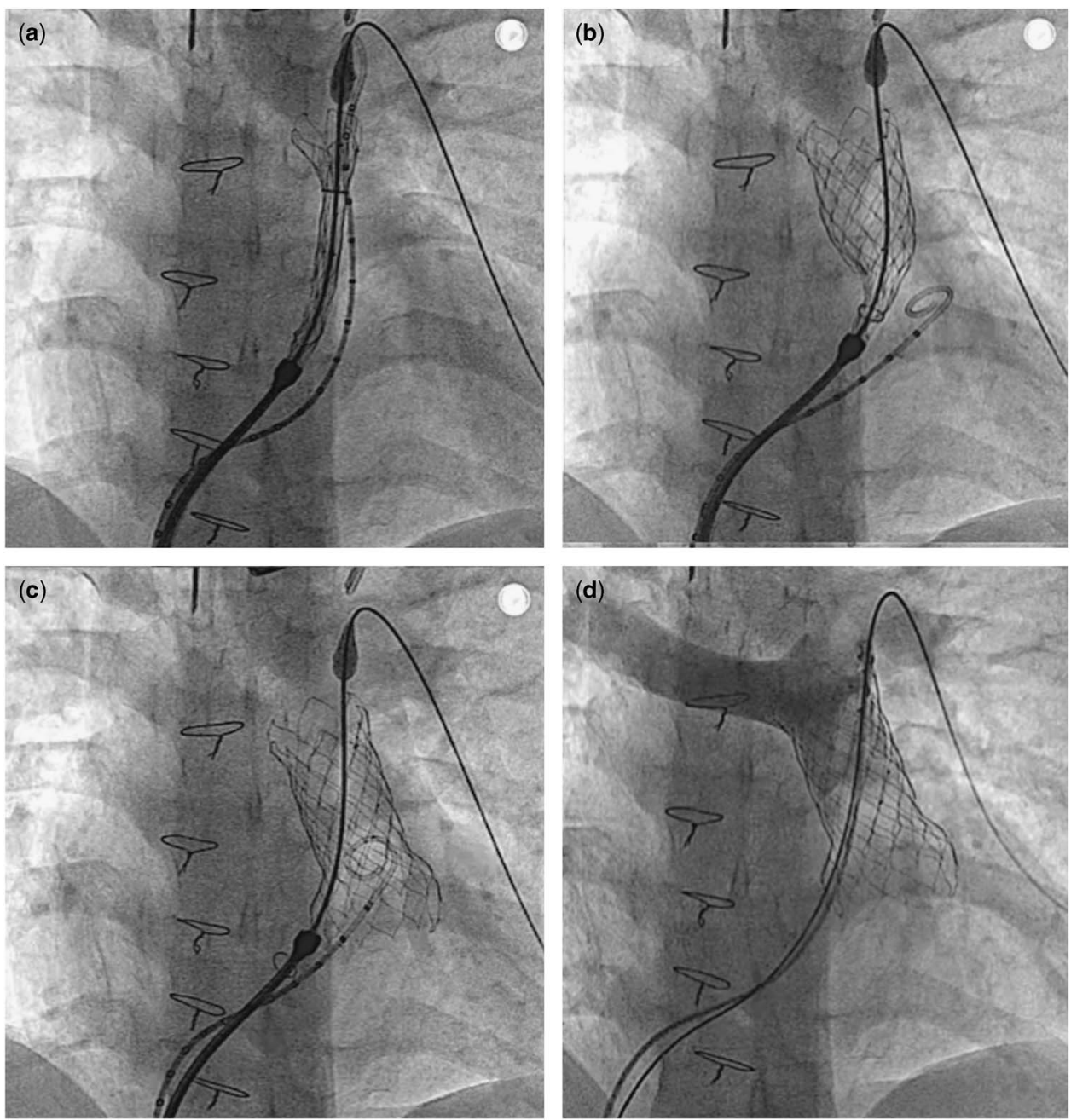

Figure 6.

Deployment sequence. The valve assembly was placed in the proximal part of the left pulmonary artery with partial exposure of the distal flare (a). By clockwise rotation of the releasing knob, the body and the proximal flare were exposed (b). After the valve was completely exposed, it was automatically detached from the delivery system and re-adjusted itself to conform to pulmonary artery anatomy (c). The delivery system was then withdrawn from the pulmonary artery. Post-implant angiography showed a competent pulmonary valve $(d)$. 
Table 1. Pre-procedural patient data.

\begin{tabular}{|c|c|c|c|c|c|c|c|c|}
\hline \multirow[b]{2}{*}{ Patient } & \multirow[b]{2}{*}{ Sex } & \multirow[b]{2}{*}{ Age (years) } & \multirow[b]{2}{*}{ Types of RVOT repair } & \multirow[b]{2}{*}{ Time after last surgery (years) } & \multicolumn{4}{|c|}{ CMR } \\
\hline & & & & & $\operatorname{RVEF}(\%)$ & PRF (\%) & RVEDVi $\left(\mathrm{ml} / \mathrm{m}^{2}\right)$ & Pulmonary valve annulus (mm) \\
\hline 1 & Male & 18.4 & TAP & 12.1 & 37 & 52 & 136 & 22 \\
\hline 2 & Female & 16.1 & TAP & 11.3 & 44 & 43 & 125 & 23 \\
\hline 3 & Male & 20.5 & TAP & 14 & 45 & 37 & 136 & 19 \\
\hline 4 & Male & 19.3 & TAP & 15.3 & 43 & 43 & 155 & 26 \\
\hline 5 & Male & 18.6 & TAP & 14.3 & 45 & 41 & 177 & 27 \\
\hline \multirow[t]{3}{*}{6} & Female & 16.3 & TAP & 10.7 & 51 & 35 & 167 & 27 \\
\hline & Median & 18.5 & & 13.5 & 44.35 & 42.15 & 146 & 24.5 \\
\hline & IQR & & & & $41.90-46.45$ & $36.2-45.37$ & $132.86-169.22$ & \\
\hline
\end{tabular}

$\mathrm{CMR}=$ cardiac magnetic resonance imaging; IQR = interquartile range; $\mathrm{PRF}=$ pulmonary regurgitation fraction; $\mathrm{RVEDVi}=$ right ventricular end-diastolic volume index; $\mathrm{RVEF}=$ right ventricular ejection fraction; $\mathrm{RVOT}=$ right ventricular outflow tract; $\mathrm{TAP}=$ transannular patch

Table 2. Procedural data.

\begin{tabular}{|c|c|c|c|c|c|c|c|c|c|c|c|c|}
\hline \multirow[b]{2}{*}{ Patient } & \multirow{2}{*}{$\begin{array}{l}\text { Maximum MPA } \\
\text { diameter }(\mathrm{mm})\end{array}$} & \multirow{2}{*}{$\begin{array}{l}\text { PA-RVOT } \\
\text { length }(\mathrm{mm})\end{array}$} & \multicolumn{3}{|c|}{ Implanted P-valve } & \multirow{2}{*}{$\begin{array}{l}\text { Procedural time } \\
\text { (min) }\end{array}$} & \multirow{2}{*}{$\begin{array}{l}\text { Fluoroscopy } \\
\text { time (min) }\end{array}$} & \multicolumn{2}{|c|}{$\operatorname{RVSP}(\mathrm{mmHg})$} & \multicolumn{2}{|c|}{ MPAP $(\mathrm{mmHg})$} & \multirow[b]{2}{*}{ Complication(s) } \\
\hline & & & Diameter $(\mathrm{mm})$ & Length $(\mathrm{mm})$ & Valve design & & & Before & After & Before & After & \\
\hline 1 & 21 & 27 & 24 & 30 & Unibody & 127 & 31.2 & 50 & 23 & 24 & 23 & \\
\hline 2 & 25 & 34 & 26 & 30 & Modular & 130 & 30.5 & 45 & 46 & 17 & 30 & Transient bradycardia \\
\hline 3 & 26 & 23 & 28 & 20 & Modular & 120 & 28.6 & 41 & 40 & 16 & 20 & \\
\hline 4 & 30 & 36 & 32 & 30 & Unibody & 112 & 29.1 & 32 & 35 & 17 & 20 & \\
\hline 5 & 24 & 32 & 26 & 30 & Unibody & 94 & 28.3 & 43 & 49 & 22 & 26 & \\
\hline 6 & 29 & 28 & 30 & 30 & Unibody & 100 & 31.3 & 37 & 45 & 21 & 23 & Valve migration \\
\hline Mean & 25.83 & 30 & & & & 113.83 & 29.83 & 41.33 & 39.66 & 19.50 & 23.66 & \\
\hline $\mathrm{SD}$ & 3.31 & 4.86 & & & & 14.56 & 1.33 & 6.28 & 9.54 & 3.27 & 3.83 & \\
\hline
\end{tabular}

$\mathrm{MPA}=$ main pulmonary artery; $\mathrm{MPAP}=$ mean pulmonary arterial pressure; $\mathrm{PA}=$ pulmonary artery; RVOT = right ventricular outflow tract; $\mathrm{RVSP}=$ right ventricular systolic pressure 

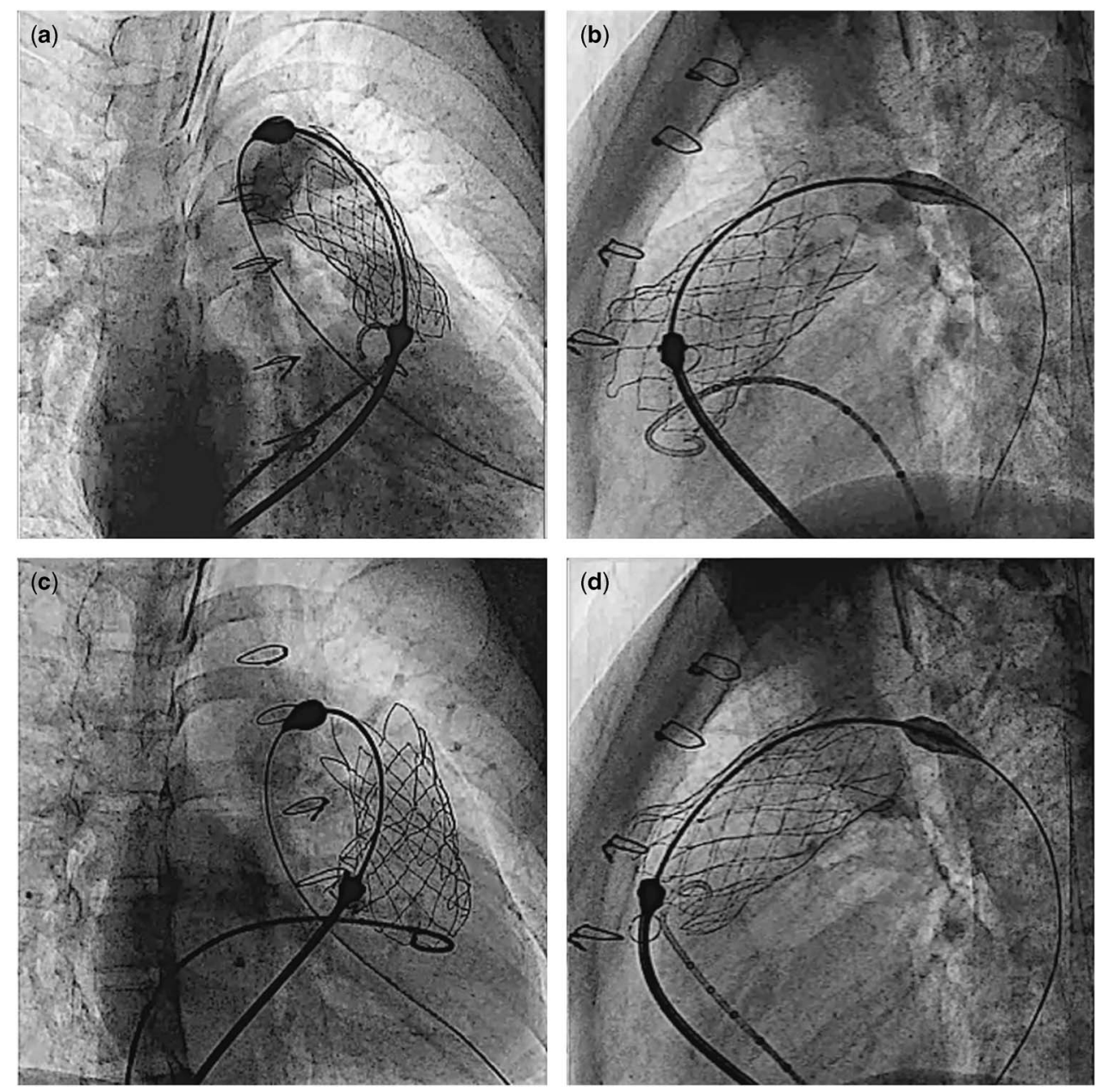

Figure 7.

Cine pictures of patient \#6. After the valve was completely exposed from the capsule, the proximal flare was not completely expanded in the right anterior oblique projection (a), whereas it appeared fully expanded in the lateral projection (b). Gentle clockwiselcounterclockwise manoeuvering of the handle of the delivery system eventually allowed complete detachment of the valve ( $\boldsymbol{c}$ and $\boldsymbol{d}$ ).

pulmonary valve implantation was analysed using Wilcoxon's Signed Ranks Test. A p-value $<0.05$ was considered to be statistically significant.

\section{Results}

Before the procedure, cardiac MRI showed that the pulmonary valve annulus diameter was between 19 and $27 \mathrm{~mm}$ (median $24.5 \mathrm{~mm}$ ). The median pulmonary regurgitant fraction was $42 \%$ (range 35-52\%, IQR 36.20-45.37\%), whereas the median right ventricular ejection fraction was $44 \%$ (range $37-51 \%$, IQR 41.90-46.45\%) and right ventricular end-diastolic volume index was $146 \mathrm{ml} / \mathrm{m}^{2}$ (range $125-177 \mathrm{ml} / \mathrm{m}^{2}$, IQR $132.86-169.22 \mathrm{ml} / \mathrm{m}^{2}$ ). All the patients had a well-preserved left ventricular systolic function with a mean left ventricular ejection fraction of $58.3 \pm 4.3 \%$ (range $53.1-64 \%$ ). The preprocedural data are summarised in Table 1.
The median time after the last surgery was 13.5 years (range 10.7-15.3 years). During the procedure, the angiographic diameter of the main pulmonary artery measured between 21 and $28 \mathrm{~mm}$ (mean $23.8 \pm 2.9 \mathrm{~mm}$ ), whereas the maximum diameter by balloon interrogation measured between 21 and $30 \mathrm{~mm}$ (mean $25.7 \pm 3.1 \mathrm{~mm}$ ). The length of the right ventricular outflow tract to the main pulmonary artery measured from 23 to $36 \mathrm{~mm}$ (mean $30 \pm 4.8 \mathrm{~mm}$ ). The difference of the measurements of the main pulmonary artery between the cardiac magnetic resonance and the balloon interrogation ranged from -2 to $4.7 \mathrm{~mm}$ (Table 2).

The Venus P-valve ${ }^{\mathrm{TM}}$ was implanted successfully in all the patients. The implanted valve diameters ranged from 24 to $32 \mathrm{~mm}$, whereas the length of the middle part was $30 \mathrm{~mm}$ in 5 and $20 \mathrm{~mm}$ in one patient. The procedure times ranged from 94 to 130 minutes (mean $114 \pm 14.6$ minutes), and the 
Table 3. Transthoracic echocardiography follow-up data.

\begin{tabular}{|c|c|c|c|c|c|c|c|}
\hline \multirow[b]{2}{*}{ Patient } & \multicolumn{2}{|c|}{ TR severity } & \multicolumn{2}{|c|}{ PR severity $(\mathrm{mmHg})$} & \multicolumn{2}{|c|}{ RVOT PG $(\mathrm{mmHg})$} & \multirow{2}{*}{$\begin{array}{l}\text { Paravalvar leak } \\
6 \text { months }\end{array}$} \\
\hline & Before & 6 months & Before & 6 months & Before & 6 months & \\
\hline 1 & Mild & Trivial & Severe & No & 8 & 40 & No \\
\hline 2 & No & No & Severe & No & 30 & 21 & No \\
\hline 3 & No & Mild & Severe & Trivial & 8 & 25 & No \\
\hline 4 & Moderate & Mild & Severe & Trivial & 6 & 10 & No \\
\hline 5 & Moderate & Mild & Severe & No & 30 & 14 & No \\
\hline 6 & Trivial & Severe & Severe & No & 5 & 4 & Mild \\
\hline
\end{tabular}

PR = pulmonary regurgitation; RVOT PG = right ventricular outflow tract pressure gradient; TR = tricuspid regurgitation; TR PG = tricuspid regurgitation pressure gradient

Table 4. Cardiac MRI follow-up data.

\begin{tabular}{|c|c|c|c|c|c|c|}
\hline \multirow[b]{2}{*}{ Patient } & \multicolumn{2}{|c|}{ RVEF (\%) } & \multicolumn{2}{|c|}{ PRF (\%) } & \multicolumn{2}{|c|}{ RVEDVi $\left(\mathrm{ml} / \mathrm{m}^{2}\right)$} \\
\hline & Before & 6 months & Before & 6 months & Before & 6 months \\
\hline 1 & 37.4 & 47.4 & 51.9 & 2.4 & 135.48 & 90.8 \\
\hline 2 & 43.9 & 56 & 43 & 2.3 & 125.02 & 74.1 \\
\hline 3 & 44.8 & 55.9 & 36.6 & 3.7 & 136.2 & 103.5 \\
\hline 4 & 43.4 & 36.9 & 43.2 & 2.1 & 155.3 & 117.9 \\
\hline 5 & 45 & 45.5 & 41.3 & 2.5 & 177.39 & 112.4 \\
\hline 6 & 50.8 & 51.5 & 35 & 8 & 166.5 & 173.58 \\
\hline Median & 44.35 & 49.45 & 42.15 & 2.45 & 145.75 & 107.95 \\
\hline IQR & $41.90-46.45$ & $43.35-55.92$ & $36.2-45.37$ & $2.25-4.77$ & $132.86-169.22$ & $86.62-131.82$ \\
\hline
\end{tabular}

$\mathrm{IQR}=$ interquartile range; $\mathrm{PRF}=$ pulmonary regurgitation fraction; $\mathrm{RVEDV} i=$ right ventricular end-diastolic volume index; $\mathrm{RVEF}=$ right ventricular ejection fraction

fluoroscopy times ranged from 28.3 to 31.3 minutes (mean $29.8 \pm 1.3$ minutes).

There was one procedure-related complication (patient \#6). Owing to incomplete detachment of the "ear" of the valve at release, the implanted valve migrated a few millimetres proximally into the right ventricle, during the retrieval of the delivery system (Fig 7). Trans-oesophageal echocardiogram of this patient showed moderate tricuspid regurgitation due to tethering of the septal leaflet from the valve scaffold. There was no outflow tract pressure gradient after the procedure. Immediate angiography in the main pulmonary artery and trans-oesophageal echocardiography after valve implantation revealed a competent pulmonary valve with minimal leakage. It was decided to continue observation of the patient. The procedural information is shown in Table 2.

Follow-up cardiac magnetic resonance and transthoracic echocardiography 6 months after implantation of the valve showed sustained reduction of the pulmonary regurgitation in all the patients (Tables 3 and 4). The median pulmonary regurgitant fraction and right ventricular end-diastolic volume index were $2.5 \%$ (range $2.1-8 \%$, IQR $2.25-4.77 \%$ ) and $108 \mathrm{ml} / \mathrm{m}^{2}$ (range $74.1-173.58 \mathrm{ml} / \mathrm{m}^{2}$, IQR 86.62 $131.82 \mathrm{ml} / \mathrm{m}^{2}$ ), respectively. The overall median pulmonary regurgitant fraction (Fig 8) and right ventricular end-diastolic volume index (Fig 9) decreased significantly 6 months after the Venus P-valve implantation. There was no evidence of paravalvar leak in any of the patients as determined by transthoracic echocardiogram. In only one patient (patient \#6), the right ventricular enddiastolic volume index increased slightly from 167 to $174 \mathrm{ml} / \mathrm{m}^{2}$ due to tricuspid regurgitation. Patient \#1 had Doppler-derived right ventricular outflow tract gradient of $40 \mathrm{mmHg}$ on echocardiography at the 6-month follow-up; however, followup cardiac magnetic resonance scan showed a pressure gradient of $17 \mathrm{mmHg}$. All the patients have remained well in NYHA functional class I, except patient \#6, who has remained in functional class II. Conservative management is being continued in this patient, with a plan to repeat the cardiac magnetic resonance study. No stent fracture was demonstrated on fluoroscopic follow-up at 6 months.

\section{Discussion}

Progressive dilation of the large right ventricular outflow tract and pulmonary regurgitation usually occurs in patients with tetralogy of Fallot after 


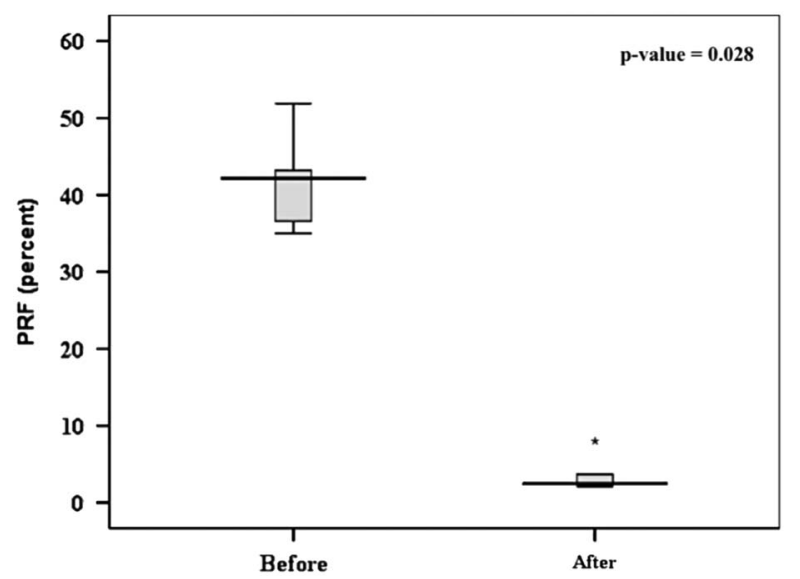

Figure 8 .

Comparison of the PRF in six patients before and 6 months after the Venus $P$-valve ${ }^{T M}$ implantation. PRF $=$ pulmonary regurgitant fraction.

previous surgical right ventricular outflow tract correction with a transannular patch. ${ }^{10}$ Percutaneous pulmonary valve implantation has been categorised as a class II American Heart Association recommendation for conduits with moderate-to-severe stenosis or regurgitation, provided the patient meets the inclusion/exclusion criteria for the available valves (Level of evidence B); ${ }^{4}$ however, only $\sim 15 \%$ of the potential patients with right ventricular outflow tract dysfunction are suitable for the currently approved implantable valves. ${ }^{11}$ At present, two commercial transcatheter heart valves systems exist: the Melody ${ }^{\mathrm{R}}$ (Medtronic Inc., Minneapolis, MN, United States of America) and the Edwards SAPIEN ${ }^{\mathrm{TM}}$ (Edwards Lifesciences, Irvine, CA, United States of America) valves. The maximum diameter for the Melody valve is $22 \mathrm{~mm}$ and for the Edwards SAPIEN ${ }^{\mathrm{TM}}$ valve is $26 \mathrm{~mm},{ }^{12}$ although the newer generation of $29 \mathrm{~mm}$ SAPIEN $\mathrm{XT}^{\mathrm{TM}}$ valve has become available for implantation in the aortic valve position. Both these valves are mounted on a balloon-expandable stent platform, and both require pre-stenting to create an optimal landing zone and to reduce the chances of stent fracture or stenosis of the framework after valve implantation. ${ }^{11-13}$ For right ventricular outflow tracts $>26-27 \mathrm{~mm}$ or native outflow tracts, which have a transannular patch or are very expansile, prestenting followed by implantation of these valves is very challenging. The concept of right ventricular outflow tract reducer was reported in 2010, but further studies with the larger-sized Medtronic valve are awaited. ${ }^{14,15}$

With a self-expanding platform design, the Venus $\mathrm{P}$-valve ${ }^{\mathrm{TM}}$ can conform to a dilated and curved structure of the right ventricular outflow tract. Furthermore, there is no need for pre-stenting to

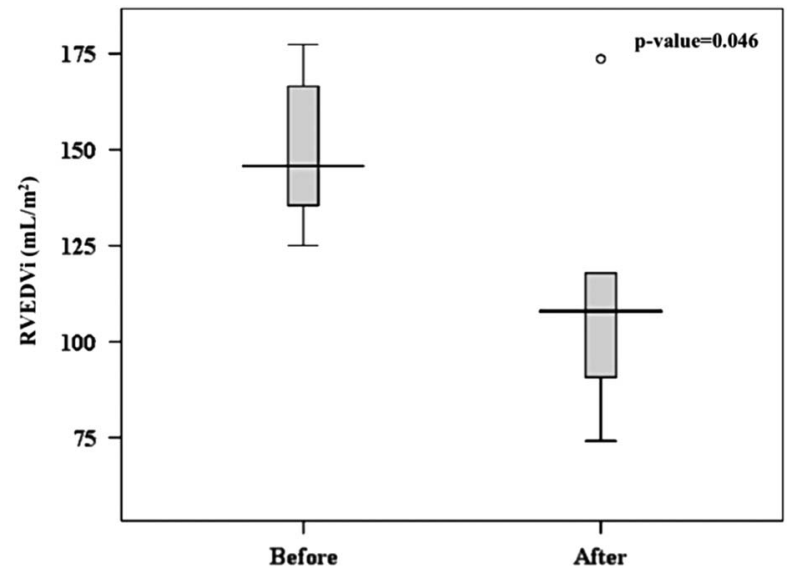

Figure 9.

Comparison of the RVEDVi in the six patients before and 6 months after valve implantation. RVEDVi = right ventricular end-diastolic volume index.

create a landing zone. This valve is currently available up to a maximum diameter of $34 \mathrm{~mm}$, which is suitable for the outflow tract diameter of up to $30-32 \mathrm{~mm}$. Furthermore, the lower radial force of the nitinol framework may reduce the likelihood of coronary artery compression after implantation. This is an important risk associated with other available valves, which need pre-stenting; ${ }^{11-13}$ however, the Venus P-valve ${ }^{\mathrm{TM}}$ is currently not suitable for patients with important fixed obstructions of the main pulmonary arteries, such as conduits, proximal pulmonary artery branches, or the right ventricular outflow tract.

There are some important technical considerations that need to be emphasised. The most crucial step for the Venus P-valve ${ }^{\mathrm{TM}}$ implantation is the initial detailed anatomical assessment. Evaluation of the stretch diameters of the right ventricular outflow tract, main pulmonary artery and its branches, as well as proximity of the coronary artery to the intended landing zone, must be performed in all cases. Although previous cardiac magnetic resonance is very helpful for the selection of patients, for the choice of the valve diameter, more detailed assessment is required. This includes previous measurements of the right ventricular outflow tract and main pulmonary artery diameter at different levels and also interrogation of the right ventricular outflow tract with a sizing balloon. We have noticed important differences of up to $4.7 \mathrm{~mm}$ between cardiac magnetic resonance and angiographic balloon measurements. Undersizing may lead to possible migration of the valve. Therefore, in order to prevent valve migration, the implanted valve diameter should be about $2-4 \mathrm{~mm}$ larger than the maximum diameter of the main pulmonary artery on balloon interrogation. This allows 

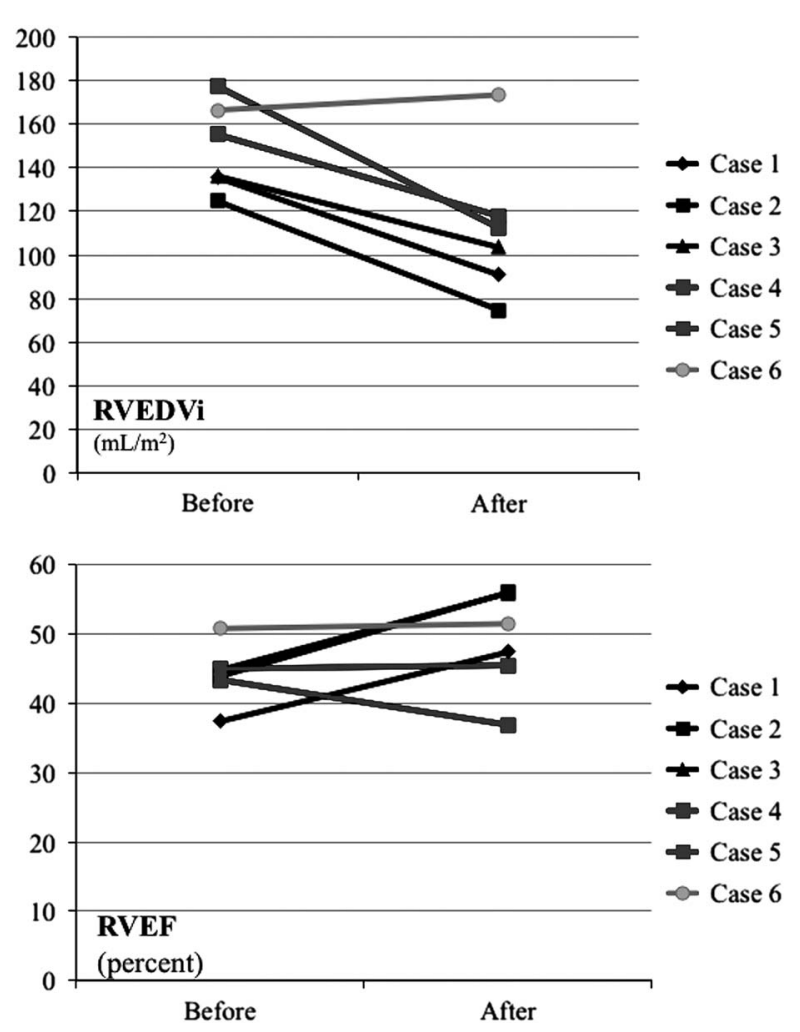

Figure 10.

The RVEDVi and RVEF in six patients before and 6 months after the valve implantation. $R V E D V i=$ right ventricular enddiastolic volume index; $R V E F=$ right ventricular ejection fraction.

the middle segment of the stent to oppose to the wall of the main pulmonary artery, thereby reducing the possibility of paravalvar leaks. In addition, the length of the middle frame should, whenever possible, match the length from the right ventricular outflow tract to the pulmonary artery bifurcation to allow the proximal and distal flares to be opposed to the pulmonary artery. For the valve deployment, it is preferable to start uncovering the distal flare of the valve in the proximal left pulmonary artery. Check angiograms are performed frequently, and the covering sheath of the valve assembly is gradually withdrawn until the distal flare is fully open within the main pulmonary artery at the bifurcation before deploying the rest of the valve. Once the middle part of the stent has been uncovered, it may not be possible to advance the valve, because the distal flare is fully expanded. Furthermore, at this stage, close monitoring of the haemodynamics is crucial, as the valve may need to be completely deployed quickly. This is because, for a short period of time, there is very little forward flow around the stent and there may be a low cardiac output. In our patients, one (patient \#6) had incomplete detachment of the valve and the delivery system after it was fully uncovered, causing unintentional valve migration a short distance into the right ventricular body. In order to avoid this problem, attention must be paid to the appearance of the proximal flare in two different fluoroscopic planes, in order to ensure the release of the attachments before attempting removal of the assembly. When the proximal flare of the valve is not fully expanded, (Fig 7), gentle clockwise/counterclockwise rotation of the handle of the delivery system may allow the "ear" of the valve to detach completely from the delivery system.

The early follow-up of the Venus P-valve ${ }^{\mathrm{TM}}$ function has been excellent. Our experience is similar to that reported by Cao et al. In their early experience with five patients, a mean follow-up time of 3.4 months demonstrated satisfactory results of the valve integrity and function, similar to our group of patients. ${ }^{6}$ Out of our six patients, five had a significant reduction of the right ventricular enddiastolic volume index and there was improvement of the right ventricular function on follow-up cardiac magnetic resonance studies. These results are comparable with the early outcomes after Melody valve and Edwards SAPIEN valve implantation in the pulmonary position. ${ }^{16,17}$

The timing of intervention in the presence of severe pulmonary regurgitation is still under evaluation. Harrild et $\mathrm{al}^{18}$ reported that late pulmonary valve replacement for symptomatic pulmonary regurgitation and right ventricular dilation did not reduce the incidence of ventricular tachycardia or death. Replacement of the pulmonary valve at a right ventricular end-diastolic volume index of $<150 \mathrm{ml} / \mathrm{m}^{2}$ may lead to normalisation of the right ventricular volumes, improvement of biventricular function, and sub-maximal exercise capacity, as described by Frigiola et al. ${ }^{8}$ Interestingly, in a recent study, patients after the repair of tetralogy of Fallot, who were free from pulmonary valve replacement in the long-term follow-up, had a mean right ventricular end-diastolic volume index of $101 \mathrm{ml} / \mathrm{m}^{2}{ }^{19}$ In our small series, two patients, who had right ventricular end-diastolic volume index of $>150 \mathrm{ml} / \mathrm{m}^{2}$, had no improvement in right ventricular ejection fraction on follow-up; however, those in whom the right ventricular end-diastolic volume index was $<150 \mathrm{ml} / \mathrm{m}^{2}$, and who had an ejection fraction of $<45 \%$, there was not only an important reduction in the right ventricular end-diastolic volume index from a mean of 132.2 to $89.5 \mathrm{ml} / \mathrm{m}^{2}$ but also an improvement in the ejection fraction from a mean of $42.0-53.1 \%$ (Fig 10). In the future, pulmonary valve replacement should be considered before the right ventricular end-diastolic volume index exceeds $150 \mathrm{ml} / \mathrm{m}^{2}$.

Stent fracture is one of the major concerns after percutaneous pulmonary valve implantation. In a series of 123 patients, who underwent Melody valve 
placement, Nordmeyer et $\mathrm{al}^{13}$ reported an incidence of stent fracture of $25 \%$ at the 2-year follow-up. With pre-stenting, this incidence has reduced. ${ }^{20}$ In a series of 22 patients with the Edwards SAPIEN ${ }^{\mathrm{TM}}$ pulmonary valve, during a short-term follow-up of 5.7 months, there was no stent fracture. ${ }^{17}$ In our small series, no pre-stenting was performed, and there was no stent fracture on fluoroscopy or structural valve failure at the 6-month follow-up. The Nitinol skeleton of the Venus P-valve ${ }^{\mathrm{TM}}$ allows the valve skeleton to adapt to the curvature of the main pulmonary artery with less tension on the framework. There may be less external compression forces on the valve skeleton in the dilated and non-obstructed right ventricular outflow tracts than in stenotic or calcified conduits; however, studies on a larger number of patients and longer follow-up are needed to evaluate the stent integrity and the valve function.

\section{Conclusion}

This study reports the feasibility and the early followup of successful Venus P-valve ${ }^{\mathrm{TM}}$ implantation in patients with severe pulmonary regurgitation after previous correction of tetralogy of Fallot, in whom a transannular patch has been used. The valve design expands the scope and the feasibility of percutaneous valve implantation in the larger outflow tracts, which are limited with the currently available percutaneous valve systems. The Venus $\mathrm{P}$-valve ${ }^{\mathrm{TM}}$ is durable in the short-term and has not shown any stent fracture or valve malfunction at 6 months after implantation. Further long-term studies are warranted.

\section{Acknowledgements}

The authors acknowledge Panthip Pattarakunwiwat, Tawatchai Kirawittaya, Chaisit Sangtawesin, Pirapat Mokarapong, Vichao Kojaranjit, Sutthirak Kuruhongsa, Nattapong Lepananon, Duenpen Horatanaruang, and Anchalee Attachoo who contributed to and facilitated the percutaneous pulmonary valve implantation procedure and patient follow-up.

\section{Financial Support}

Venus Medtech, Shanghai, China, donated the Venus $\mathrm{P}$-valves used in this study.

\section{Conflicts of Interest}

None.

\section{Ethical Standards}

The authors assert that all procedures contributing to this work comply with the ethical standards of the relevant national guidelines on human experimentation and with the Helsinki Declaration of 1975, as revised in 2008, and has been approved by the Queen Sirikit National Institute of Child Health ethical committees.

\section{Supplementary material}

To view supplementary material for this article, please visit http://dx.doi.org/10.1017/S1047951 115001067

\section{References}

1. Bonhoeffer P, Boudjemline Y, Saliba Z, et al. Percutaneous replacement of pulmonary valve in a right ventricle to pulmonary artery prosthetic conduit with valve dysfunction. Lancet 2000; 356 : 1403-1405.

2. Baumgartner H, Bonhoeffer P, De Groot NM, et al. Task force on the management of grown-up congenital heart disease of the European Society of Cardiology (ESC); Association for European Paediatric Cardiology (AEPC). ESC guidelines for the management of grown-up congenital heart disease (new version 2010). Eur Heart J 2010; 31: 2915-2957.

3. Eicken A, Ewert P, Hager A, et al. Percutaneous pulmonary valve implantation two-centre experience with more than 100 patients. Eur Heart J 2011; 32: 1260-1265.

4. Feltes TF, Bacha E, Beekman RH 3rd, et al. Indications for cardiac catheterization and intervention in pediatric cardiac disease: a scientific statement from American Heart Association. Circulation 2011; 123: 2607-2652.

5. Cao QL, Lam YY, Gao W. Venus P-valve. Percutaneous valve bioprosthesis system: Animal Test Report, Report No. PCR1128J, Gateway Medical Innovation Center, Shangai, 2013 March, 16p.

6. Cao QL, Kenny D, Zhou D, et al. Early clinical experience with a novel self-expanding percutaneous stent-valve in the native right ventricular outflow tract. Catheter Cardiovasc Interv 2014; 84: $1131-1137$.

7. Joyce JJ, Hwang EY, Wiles HB, Kline CH, Bradley SM, Crawford FA Jr. Reliability of intraoperative transesophageal echocardiography during tetralogy of Fallot repair. Echocardiography 2000; 17: 319-327.

8. Frigiola A, Tsang V, Bull C, et al. Biventricular response after pulmonary valve replacement for right ventricular outflow tract dysfunction: is age a predictor of outcome? Circulation 2008; 118 : S182-S190.

9. Yock PG, Popp RL. Noninvasive estimation of right ventricular systolic pressure by Doppler ultrasound in patients with tricuspid regurgitation. Circulation 1984; 70: 657-662.

10. de Ruijter FT, Weenink I, Hitchcock FJ, Meijboom EJ, Bennink GB. Right ventricular dysfunction and pulmonary valve replacement after correction of tetralogy of Fallot. Ann Thorac Surg 2002; 73: 1794-1800.

11. Demkow M, Biernacka EK, Spiewak M, et al. Percutaneous pulmonary valve implantation preceded by routine prestenting with a bare metal stent. Catheter Cardiovasc Interv 2011; 77: 381-389.

12. Kenny D, Hijazi ZM, Kar S, et al. Percutaneous implantation of the Edwards SAPIEN transcatheter heart valve for conduit failure in the pulmonary position: early phase 1 results from an international multicenter clinical trial. J Am Coll Cardiol 2011; 21: 2248-2256. 
13. Nordmeyer J, Khambadkone S, Coats L, et al. Risk stratification, systematic classification and anticipatory management strategies for stent fracture after percutaneous pulmonary valve implantation. Circulation 2007; 115: 1392-1397.

14. Schievano S, Taylor AM, Capelli C, et al. First-in-man implantation of a novel percutaneous valve: a new approach to medical device development. EuroIntervention 2010; 5: 745-750.

15. Biglino G, Capelli C, Binazzi A, et al. Virtual and real bench testing of a new percutaneous valve device: a case study. EuroIntervention 2012; 8: 120-128.

16. Hasan BS, McElhinney DB, Brown DW, et al. Short-term performance of the transcatheter melody valve in high-pressure hemodynamic environments in the pulmonary and systemic circulations. Circ Cardiovasc Interv 2011; 4: 615-620.
17. Haas NA, Moysich A, Neudorf U, et al. Percutaneous implantation of the Edwards SAPIEN ${ }^{\mathrm{TM}}$ pulmonic valve: initial results in the first 22 patients. Clin Res Cardiol 2013; 2: 119-128.

18. Harrild DM, Berul CI, Cecchin F, et al. Pulmonary valve replacement in tetralogy of Fallot: impact on survival and ventricular tachycardia. Circulation 2009; 119: 445-451.

19. Frigiola A, Hughes M, Turner M, et al. Physiological and phenotypic characteristics of late survivors of tetralogy of Fallot repair who are free from pulmonary valve replacement. Circulation 2013; 128: 1861-1868.

20. McElhinney DB, Cheatham JP, Jones TK, et al. Stent fracture, valve dysfunction, and right ventricular outflow tract reintervention after transcatheter pulmonary valve implantation: patientrelated and procedural risk factors in the US melody valve trial. Circ Cardiovasc Interv 2011; 6: 602-614. 